\title{
Ensino Embasado na Estrutura Conceitual: a escolha da metodologia ativa, para aplicação de casos para ensino, importa?
}

\author{
Gleison de Abreu Pontes \\ https://orcid.org/0000-0002-8421-342X | E-mail: gleison.orientador@gmail.com \\ Kellma Bianca Cardoso Fonseca \\ https://orcid.org/0000-0001-7306-0029 | E-mail:kellma.fonseca@ufu.br \\ Ariane Caruline Fernandes \\ https://orcid.org/0000-0003-1551-0081 | E-mail: ariane_161@hotmail.com \\ Patrícia de Souza Costa \\ https://orcid.org/0000-0001-5087-1419 | E-mail:patricia.costa@ufu.br
}

\section{Resumo}

Objetivo: Para demonstrar os benefícios das metodologias ativas, o estudo propõe identificar quais habilidades e competências são desenvolvidas na aplicação de casos e técnicas de ensino diferentes, à luz do Ensino Embasado na Estrutura Conceitual (EEEC) e da Taxonomia de Bloom (TB).

Método: Foram testadas as técnicas Grupo de Verbalização e de Observação (GV-GO), Júri Simulado e Problem-Based Learning (PBL). A percepção dos discentes foi coletada por meio de questionário e aprofundada com um grupo focal.

Resultados: Na percepção dos estudantes, o emprego das técnicas desenvolveu habilidades e competências distintas. Assim, a escolha da metodologia para aplicação de casos deve estar alinhada com os objetivos educacionais estabelecidos pelo docente. Apesar de terem sido desenvolvidas competências de todos os estágios do EEEC, as técnicas de ensino GV-GO e PBL desenvolveram mais as competências do estágio avançado do EEEC, enquanto a do Júri Simulado do estágio intermediário.

Contribuições: Os resultados podem ser úteis para docentes de áreas distintas intensificarem o processo de ensino-aprendizagem com a aplicação de metodologias ativas, e para o International Accounting Standard Board (Iasb) ir além do desenvolvimento de casos para ensino no EEEC, incorporando na agenda reflexões sobre quais metodologias utilizar na aplicação desses materiais no instituto de favorecer a compreensão e a aplicação coerente das International Financial Reporting Standards(IFRS).

Palavras-chave: Metodologias ativas; EEEC; Casos para ensino; Competências. 


\section{Introdução}

A aplicação coerente das IFRS requer dos estudantes competências relacionadas à realização de julgamentos, a capacidade de lidar com incertezas, de fazer escolhas e estimativas (Barth, 2008). Alinhado a isso, o Iasb desenvolveu materiais de ensino em contabilidade, compondo o intitulado Ensino Embasado na Estrutura Conceitual (EEEC), em inglês Framework Based-Teaching, com o intuito de auxiliar docentes, discentes, profissionais da área contábil e Instituições de Ensino Superior (IES) no processo de ensino-aprendizagem das IFRS (Wells, 2011). Especificamente, o EEEC visa ao desenvolvimento e/ ou aprimoramento de habilidades e competências, principalmente para a compreensão e a aplicação consistente das IFRS, dividindo o ensino em três estágios: conscientização, compreensão e competência (Costa, Gomes, Braunbeck, \& Santana, 2018; Wells, 2011;Wells \& Tarca, 2014). Nessa perspectiva, o ensino das IFRS ocorre de maneira gradual, coincidindo esses três estágios com as disciplinas introdutórias, intermediárias e avançadas do curso de Ciências Contábeis, respectivamente (Costa et al., 2018).

Os materiais didáticos desenvolvidos pelo Iasb para o EEEC caracterizam-se como casos para ensino, visto que correspondem à problematização de situações do contexto profissional no processo de ensino-aprendizagem (Alberton \& Silva, 2018). O caso para ensino Open Safari, elaborado especificamente para o estágio 3 do EEEC, leva os estudantes a raciocinar conceitualmente e a formular políticas contábeis consistentes com a Estrutura Conceitual, bem como exercerem estimativas e julgamentos(Wells \& Tarca, 2014). Essa escolha por casos pode ser justificada pelo fato desses materiais auxiliarem no desenvolvimento de habilidades e competências necessárias ao profissional da contabilidade (Januário, Pinho, Gonçalves, \& Araújo, 2020; Costa et al., 2018). Sobre o alcance deste objetivo, Costa et al. (2018) identificaram que, na percepção dos estudantes de Ciências Contábeis, o caso para ensino Open Safari, aplicado com a técnica de ensino PBL, auxiliou os estudantes no desenvolvimento de habilidades e competências dos domínios cognitivo e afetivo da TB.

Nesse sentido, os estágios do EEEC possuem associação com as habilidades e competências dos domínios cognitivo e afetivo da TB, o que implica dizer que, mesmo em disciplinas do estágio inicial, os estudantes podem desenvolver habilidades e competências do estágio intermediário e avançado do EEEC, e vice-versa (Costa et al., 2018). Costa, Ávila, Santos e Cruz (2020) também encontraram essa associação, porém evidenciaram resultados díspares aos de Costa et al. (2018)quanto às competências desenvolvidas com a aplicação da técnica de ensino role-play em uma disciplina do estágio 1 do EEEC. Esses resultados sugerem que seja possível usar estratégias de ensino distintas para o desenvolvimento de habilidades e competências dos domínios cognitivo e afetivo da TB em todos os estágios do EEEC, sendo que estratégias diferentes desenvolvem habilidades e competências diferentes.

Diante desse contexto, tem-se que casos para ensino podem ser aplicados com o emprego de estratégias de ensino distintas, e que tanto o caso quanto a estratégia adotada para sua aplicação podem auxiliar os estudantes no desenvolvimento de habilidades e competências díspares (Costa et al., 2018; Costa et al., 2020). Nessa linha de pensamento, Januário et al. (2020) identificaram que, na visão dos estudantes, a metodologia ativa utilizada para aplicação do caso para ensino pode ter impacto diferenciado no processo de ensino-aprendizagem. No entanto, esses autores não associaram tal percepção com o desenvolvimento de habilidades e competências. Ademais, Costa et al. (2018) e Costa et al. (2020) aplicaram as técnicas PBL e role-play em turmas dos estágios 3 e 1, respectivamente, e em momentos distintos, o que não permite avaliar se técnicas distintas desenvolvem habilidades e competências distintas em uma mesma turma.

Ressalta-se que o Iasb, por meio do EEEC, produziu materiais para ensino das IFRS que pudessem desenvolver habilidades e competências consideradas relevantes por esse órgão para a formação do profissional da contabilidade, porém não discutiu formas de aplicação desses materiais. Assim, identificar quais metodologias ativas auxiliam no desenvolvimento das habilidades e competências requeridas do profissional da contabilidade constitui uma lacuna de pesquisa relevante para o aprimoramento do EEEC. 
Destarte, o objetivo desta pesquisa é identificar quais habilidades e competências são desenvolvidas na resolução de casos para o ensino com a aplicação de técnicas de ensino diferentes. Essa análise foi realizada à luz da TB e do EEEC. A pesquisa foi empreendida com graduandos do curso de Ciências Contábeis de uma universidade pública mineira. Foram testadas as técnicas de ensino GV-GO, Júri Simulado e PBL, na aplicação de três casos para ensino distintos. A percepção dos discentes foi coletada por meio de questionário aplicado ao término de cada técnica de ensino empregada e complementada com um grupo focal ao final da disciplina de Contabilidade Introdutória II (primeiro estágio do EEEC).

A técnica GV-GO é recomendada, principalmente, para o desenvolvimento de habilidades distintas de síntese por estudantes na construção do conhecimento (Anastasiou \& Alves, 2004). O GV examina e discute uma situação proposta pelo docente, o GO analisa criticamente as discussões. Na sequência, o papel dos grupos é invertido, passando o GV a escutar enquanto o GO tece suas contribuições (Saldanha, Guerra, Firmino, Vasconcelos \& Sampaio, 2019). O Júri Simulado apresenta objetivo semelhante à técnica GV-GO, contudo, sua dinâmica consiste em atribuir o papel da acusação para um grupo de estudantes e o papel da defesa para outro (Thiesen, Giovanaz, Rieger, \& Bernhard, 2017). Devido à simulação de um ambiente de júri, a aplicação dessa técnica possibilita um amplo envolvimento dos estudantes (Anastasiou \& Alves, 2004). Já a PBL estimula, sobretudo, a responsabilidade dos discentes pelo próprio aprendizado e o desenvolvimento de um conhecimento mais aprofundado e significativo, podendo ser conduzida sob a orientação de sete etapas e aplicação em mais de uma sessão tutorial (Soares, Botinha, Casa Nova, Soares, \& Bulaon, 2017). Os casos para ensino aplicados utilizando as técnicas de ensino GV-GO, Júri Simulado e PBL constituem uma oportunidade de desenvolver habilidades e competências resultantes da associação entre o EEEC e a TB.

Os resultados desta pesquisa contribuem com a literatura sobre a validade dos fundamentos do EEEC, ao mostrarem que a efetividade dos casos para ensino para o desenvolvimento de habilidades e competências é, em parte, dependente da metodologia ativa utilizada para aplicá-lo, e também com a literatura sobre a eficácia do uso de metodologias ativas no processo de ensino-aprendizagem no ensino superior. Mais especificamente, os resultados deste estudo contribuem com a avaliação do uso das técnicas de ensino GV-GO, Júri Simulado e PBL, em casos para ensino, no que tange ao desenvolvimento de habilidades e competências, requeridas pelo profissional da contabilidade, nas disciplinas iniciais do curso, estágio 1 do EEEC. Além disso, os resultados podem ser úteis para o Iasb refletir sobre como aplicar os casos para ensino desenvolvidos no EEEC, uma vez que aquele órgão ainda não traz informações sobre como aplicar esses casos de maneira a atingir os objetivos do EEEC.

\section{Revisão da Literatura e Hipóteses de Pesquisa}

A adoção das IFRS tem implicações tanto na prática contábil como no ensino da contabilidade (Carvalho \& Salotti, 2013). Nesse contexto, um dos principais desafios é preparar os discentes para a aplicação consciente de conceitos inerentes às normas e aos relatórios financeiros baseados em princípios (Barth, 2008). Diante disso, o Iasb desenvolveu materiais de ensino em contabilidade com o intuito de auxiliar as IES no processo de ensino-aprendizagem das IFRS (Costa et al., 2018). Importa ressaltar que o EEEC tem como principal objetivo auxiliar os estudantes no desenvolvimento e no aprimoramento de habilidades e competências para a compreensão e a aplicação coerente das IFRS (Costa et al., 2018; Wells, 2011). 
De acordo com Wells e Tarca (2014), o EEEC divide o ensino das IFRS em três estágios: conscientização, compreensão e competência. No primeiro estágio, os estudantes tomam consciência da existência de julgamentos e estimativas para a aplicação das IFRS. No segundo estágio, aprofundamse no conteúdo trabalhado no primeiro por meio do conhecimento de trechos da Estrutura Conceitual. No terceiro estágio, o da competência, por meio dos princípios fundamentais das normas, os estudantes reconhecem as transações e os eventos, e sabem classificar as transações e aplicar os requerimentos estabelecidos nas normas (Costa et al., 2018; Wells, 2011; Wells \& Tarca, 2014). Esses estágios coincidem com as disciplinas introdutórias, intermediárias e avançadas do curso de Ciências Contábeis, respectivamente (Costa et al., 2018).

Tanto o EEEC quanto a TB estabelecem o desenvolvimento gradual de habilidades e competências por meio de estágios e domínios, respectivamente. A TB preconiza que o processo de ensino-aprendizagem deve partir de algo mais simples para um mais complexo, com o intuito de estimular os estudantes na busca de experiências comportamentais (Bloom, Engelhart, Furst, Hill, \& Krathwohl, 1983). Nesse sentido, a TB classifica as oportunidades de aprendizagem em três domínios principais: cognitivo, afetivo e psicomotor.

O domínio cognitivo trata da aprendizagem intelectual, compreendendo a aquisição de novos conhecimentos, competências e atitudes, é composto de seis categorias: conhecimento, compreensão, aplicação, análise, síntese e avaliação (Bloom et al., 1983). É possível o discente lembrar informações (conhecimento), dar significado ao conteúdo (compreensão), usar informações, métodos e conteúdo em novas situações (aplicação), identificar e analisar partes de conteúdo e suas inter-relações (análise), organizar, agregar e juntar partes da aprendizagem com a finalidade de criar um novo "todo" (síntese) e, ainda, julgar a partir de critérios bem definidos o valor do conhecimento (avaliação) (Ferraz \& Belhot, 2010).

O domínio afetivo envolve sentimentos e posturas e está relacionado ao desenvolvimento emocional e afetivo do indivíduo, o qual é composto de cinco categorias: receptividade, resposta, valorização, organização e caracterização (Bloom, Engelhart, Furst, Hill, \& Krathwohl, 1974). As habilidades e competências desenvolvidas no nível afetivo significam que o indivíduo aceitou o conhecimento, auxiliando, assim, o desenvolvimento do nível cognitivo. Logo, disposição, responsabilidade, interesse e participação são aspectos da ordem deste domínio (Bloom et al., 1974). De acordo com a TB, o indivíduo só ascende a uma nova categoria, nos três domínios, quando alcança desempenho adequado na categoria anterior, pois cada uma recorre a capacidades adquiridas nos níveis anteriores (Ferraz \& Belhot, 2010), o que é análogo à filosofia dos estágios no EEEC.

Ferraz e Belhot (2010) esclarecem que a TB permite o planejamento e a escolha do instrumento de aprendizagem que pode ser trabalhado de forma integrada e estruturada, considerando que todos os indivíduos têm capacidade de aprender e que se diferem somente em relação ao nível de profundidade e abstração do conhecimento de cada um. Tal diferença pode ser caracterizada pelo método utilizado e pela organização do processo de ensino-aprendizagem, por isso, é importante a escolha adequada de estratégias, métodos de ensino e a delimitação do conteúdo específico (Ferraz \& Belhot, 2010).

Costa et al. (2018) e Costa et al. (2020) associaram os estágios do EEEC e os domínios cognitivo e afetivo da TB e mostraram efetividade no alcance dos objetivos propostos pelo EEEC. Assim, esses domínios são o foco deste trabalho. Costa et al. (2018) afirmam que no primeiro estágio do EEEC seriam desenvolvidas as categorias de conhecimento, compreensão e aplicação do domínio cognitivo da TB. No segundo estágio, a categoria de análise seria acrescentada a essas três categorias iniciais, e seriam desenvolvidas todas as categorias do domínio cognitivo da TB no terceiro estágio. Costa et al. (2020) declaram que o domínio afetivo pode se mostrar fundamental para o desenvolvimento das categorias de conhecimento e da compreensão, abordados nos estágios 1, 2 e 3 do EEEC. Essas autoras evidenciaram que as categorias do domínio cognitivo da TB interagem entre si com o domínio afetivo, sugerindo que existe simultaneidade entre elas. E, ainda, o domínio afetivo da TB auxilia no desenvolvimento das categorias cognitivas e vice-versa (Costa et al., 2020). A associação entre os domínios cognitivo e afetivo da TB e os estágios do EEEC é demonstrada na Tabela 1. 
Tabela 1

Associação entre a TB e os estágios do EEEC

\begin{tabular}{lccc}
\hline \multicolumn{1}{c}{ Domínios } & Estágio 1 - EEEC & Estágio 2 - EEEC & Estágio 3 - EEEC \\
\hline Cognitivo & & & \\
\hline 1. Conhecimento & $\bullet$ & $\bullet$ & $\cdot$ \\
\hline 2. Compreensão & $\bullet$ & $\bullet$ & $\cdot$ \\
\hline 3. Aplicação & $\bullet$ & $\cdot$ & $\cdot$ \\
\hline 4. Análise & & & $\cdot$ \\
\hline 5. Síntese & & & $\cdot$ \\
\hline 6. Avaliação & & $\bullet$ & $\cdot$ \\
\hline Afetivo & $\bullet$ & & \\
\hline
\end{tabular}

Fonte: adaptado de Costa et al. (2018) e Costa et al. (2020).

Percebe-se que Costa et al. (2018) e Costa et al. (2020) empregaram metodologias de aprendizagem ativas como forma de intensificarem o processo de ensino-aprendizagem. As metodologias ativas consistem em métodos de ensino que possibilitam ao estudante desenvolver o aprendizado por meio da sua própria responsabilidade, fazendo com que deixe de ser um sujeito passivo e participe ativamente do processo de ensino-aprendizagem (Sauaia, 2006). Essas metodologias baseiam-se em como auxiliar o estudante no processo de aprendizagem por meio de experiências reais ou simuladas, com o objetivo de solucionar os desafios que possam surgir na prática social (Berbel, 2011). Coetzee e Schmulian (2013) destacam que o estilo tradicional, na transmissão de conhecimento de forma passiva, não proporciona, por si só, o desenvolvimento de habilidades críticas, analíticas e de julgamento. Assim, as metodologias de ensino desenvolvem diferentes competências e auxiliam no enriquecimento do conteúdo e no alcance dos objetivos educacionais (Leal \& Borges, 2016).

Nagib e Silva (2020) expõem que a técnica de ensino utilizada pelo docente pode auxiliar o estudante no desenvolvimento de diferentes competências. Então, aplicar casos para ensino com técnicas de ensino distintas permite desenvolver comportamentos e competências diferentes no processo de ensinoaprendizagem. Nesse sentido, a técnica de ensino GV-GO se associa ao autocontrole, à interação social, à criatividade e à expressão oral (Oliveira \& Campos, 2017). A técnica de ensino Júri Simulado propicia confrontar pontos de vista e diferentes posições em uma disputa intelectual (Moura, Pereira \& Souza, 2017). A técnica de ensino PBL desenvolve conhecimentos, habilidades e atitudes na resolução de problemas reais que surgem na prática empresarial (Soares, Botinha, Casa Nova, Soares \& Bulaon, 2017). Na Tabela 2,é demonstrada a síntese das habilidades e competências que podem ser desenvolvidas com a aplicação dessas técnicas de ensino, em conformidade com os domínios da TB proposta por Bloom et al. (1974). 
Tabela 2

Técnicas de ensino versus habilidades e competências

\begin{tabular}{|c|c|c|c|c|}
\hline Técnica & Definição & Habilidades e competências & TB & Fonte \\
\hline \multirow{7}{*}{ GV-GO } & \multirow{7}{*}{$\begin{array}{l}\text { É uma técnica de ensino em que se divide } \\
\text { a sala de aula em dois grupos: um de } \\
\text { verbalização (GV) e um de observação } \\
\text { (GO). O GV tem a obrigação de verbalizar } \\
\text { sobre o tema proposto pelo professor, } \\
\text { e o GO observar se os conceitos estão } \\
\text { sendo discutidos adequadamente. }\end{array}$} & Autocontrole & $\mathrm{AF}$ & \multirow{7}{*}{$\begin{array}{l}\text { Masetto (2003); } \\
\text { Nagib (2018); } \\
\text { Oliveira e Campos } \\
\text { (2017). }\end{array}$} \\
\hline & & Criatividade & $\mathrm{AF}$ & \\
\hline & & Interação social & $\mathrm{AF}$ & \\
\hline & & Liderança & PS & \\
\hline & & Oratória e comunicação verbal & $\mathrm{CO}$ & \\
\hline & & Pensamento crítico & $\mathrm{CO}$ & \\
\hline & & Respeito as opiniões dos outros & $\mathrm{AF}$ & \\
\hline \multirow{4}{*}{$\begin{array}{l}\text { Júri } \\
\text { Simulado }\end{array}$} & \multirow{4}{*}{$\begin{array}{l}\text { É entendido como uma discussão } \\
\text { formal em que se contrapõem duas ou } \\
\text { mais opiniões a respeito de um tema, } \\
\text { geralmente, considerado polêmico, } \\
\text { em que ambas as partes procuram } \\
\text { convencer uma terceira parte. }\end{array}$} & Agilidade mental & PS & \multirow{4}{*}{$\begin{array}{l}\text { Moura et al. } \\
\text { (2017); Thiesen, } \\
\text { Giovanaz, Rieger e } \\
\text { Bernhard. (2017). }\end{array}$} \\
\hline & & Argumentação & $\mathrm{CO}$ & \\
\hline & & Pensamento crítico & $\mathrm{CO}$ & \\
\hline & & Trabalho em equipe & $\mathrm{CO}$ & \\
\hline \multirow{7}{*}{ PBL } & \multirow{7}{*}{$\begin{array}{l}\text { É um método centrado na discussão e } \\
\text { tem foco na resolução de problemas. } \\
\text { Direciona o indivíduo para um } \\
\text { conhecimento mais profundo e } \\
\text { significativo, permitindo a coragem e } \\
\text { responsabilidade da aprendizagem } \\
\text { individual do estudante. }\end{array}$} & Curiosidade intelectual e cultural & $\mathrm{AF}$ & \multirow{7}{*}{$\begin{array}{l}\text { Coetzee e } \\
\text { Schmuliam (2013); } \\
\text { Jackling, De Lange } \\
\text { e Natoli (2013); } \\
\text { Heinz et al. (2019); } \\
\text { Soares et al. } \\
\text { (2017). }\end{array}$} \\
\hline & & Interdisciplinaridade & $\mathrm{CO}$ & \\
\hline & & Pensamento crítico & $\mathrm{CO}$ & \\
\hline & & Dever pelo próprio aprendizado & $\mathrm{AF}$ & \\
\hline & & Solucionar problemas práticos & $\mathrm{CO}$ & \\
\hline & & Tomada de decisão & $\mathrm{CO}$ & \\
\hline & & Trabalho em equipe & $\mathrm{CO}$ & \\
\hline
\end{tabular}

Nota: TB: Taxonomia de Bloom; AF: domínio afetivo; CO: domínio cognitivo; PS: domínio psicomotor.

Fonte: elaborada pelos autores.

Diante das diferenças entre as técnicas de ensino (Tabela 2), o docente, na escolha das metodologias ativas para uso no processo de ensino-aprendizagem, deve analisar os objetivos pedagógicos da disciplina/ conteúdo, conhecer o perfil da turma (Marion, Garcia \& Cordeiro,2009), bem como o tempo disponível para aplicação das técnicas, a complexidade dos elementos considerados nas atividades e a característica do ambiente de ensino que deve proporcionar liberdade, decisões e julgamentos de soluções (Soares et al., 2017). Dessa forma, as metodologias ativas são recursos que, quando alinhadas com os objetivos pedagógicos, podem contribuir com a construção de habilidades e competências (Nagib \& Silva, 2020).

Destarte, as metodologias ativas podem auxiliar no alcance dos objetivos propostos pelo EEEC e estabelecidos nos domínios cognitivo e afetivo da TB, pois, como Costa et al. (2018) e Costa et al. (2020) demonstraram, na utilização dessas estratégias em sala de aula, os discentes se tornaram mais ativos no processo de ensino-aprendizagem. Além disso, essas estratégias possibilitam relacionar teoria com exemplos práticos, conciliar os temas aprendidos nos casos para ensino com outras disciplinas, buscar informações e desenvolver habilidades afetivas e cognitivas, na percepção dos estudantes. Especificamente, esses autores identificaram que as metodologias ativas aplicadas auxiliaram no desenvolvimento de todas as habilidades e competências da categoria do domínio cognitivo da TB e não apenas das três primeiras categorias (conhecimento, compreensão e aplicação), sugerindo que os estudantes podem desenvolver habilidades e competências do estágio intermediário e avançado do EEEC, mesmo cursando disciplinas do estágio inicial e, vice-versa, fora as ligadas ao domínio afetivo. Assim, os objetivos do EEEC, com a utilização de metodologias ativas, foram alcançados. Diante desse contexto, tem-se a primeira hipótese de pesquisa:

- $H_{1}$ : A aplicação das técnicas de ensino GV-GO, Júri Simulado e PBL na resolução de casos para ensino desenvolve habilidades e competências distintas, de acordo com a percepção dos estudantes. 
Costa et al. (2018) identificaram a percepção dos estudantes sobre a utilidade da técnica de ensino PBL aplicada na discussão do caso para ensino Open Safari em uma disciplina do estágio 3 do EEEC. Já Costa et al. (2020) observaram a percepção dos estudantes com a aplicação da técnica roleplay no desenvolvimento de habilidades e competências do primeiro estágio do EEEC. Esses autores identificaram que ambas as técnicas desenvolvem habilidades e competências requeridas pelo EEEC e que estas estão alinhadas com os domínios cognitivo e afetivo da TB. Porém, as habilidades e as competências desenvolvidas foram diferentes quando da utilização do PBL e do role-play, o que conduz à segunda hipótese de pesquisa:

- $\quad \mathrm{H}_{2}$ : A aplicação das técnicas de ensino GV-GO, Júri Simulado e PBL na resolução de casos para ensino desenvolve de maneira diferente os estágios do EEEC.

\section{Procedimentos Metodológicos}

A pesquisa é do tipo descritiva, em face do objetivo, o levantamento dos dados e em relação aos procedimentos técnicos classificam-se como uma abordagem quali-quantitativa. Esta seção está dividida em duas partes: na primeira, é descrito como as técnicas foram aplicadas em sala de aula, bem como o tema dos casos para ensino. Na segunda sub-seção, é ilustrado o conteúdo do questionário e como ele foi aplicado. Além disso, também é apresentada a metodologia empregada na realização do grupo focal.

\subsection{Aplicação das técnicas de ensino: GV-GO, Júri Simulado e PBL}

As técnicas de ensino GV-GO, Júri Simulado e PBL foram escolhidas, intencionalmente, pelos docentes da disciplina de Contabilidade Introdutória II, de acordo com o objetivo de aprendizagem fixado para as aulas de cada conteúdo ministrado. As referidas técnicas foram usadas na aplicação de casos para ensino preparados para três conteúdos constantes do programa dessa disciplina, respectivamente: i) Fundo Fixo de Caixa e Conciliação Bancária; ii) Duplicatas em Carteira, Cobrança Simples e Desconto de Duplicatas; e iii) Provisões, Passivos e Ativos Contingentes. Uma breve descrição do conteúdo desses casos é exposta na Tabela 3.

Tabela 3

Tema abordado nos casos para ensino

\begin{tabular}{ll}
\hline \multicolumn{1}{c}{ Tema } & \multicolumn{1}{c}{ Caso } \\
\hline $\begin{array}{l}\text { Fundo Fixo e Conciliação } \\
\text { Bancária }\end{array}$ & $\begin{array}{l}\text { O caso apresenta dados reais de um sindicato que passa por problemas de conciliação } \\
\text { bancária, gestão das disponibilidades e controle interno. Os estudantes, no papel de } \\
\text { consultores, devem propor soluções para os problemas elencados no caso. }\end{array}$ \\
\hline $\begin{array}{l}\text { Provisões e Passivos } \\
\text { Contingentes }\end{array}$ & $\begin{array}{l}\text { O foco do caso é refletir os critérios para a identificação, mensuração e reconhecimento } \\
\text { das provisões e passivos contingentes a partir do contexto de rompimento das barragens } \\
\text { do Fundão e de Brumadinho. }\end{array}$ \\
\hline $\begin{array}{l}\text { Duplicatas em Carteira, } \\
\text { Cobrança Simples e } \\
\text { Descontadas }\end{array}$ & $\begin{array}{l}\text { O intuito do caso é levar os estudantes para um contexto de análise de transações } \\
\text { envolvendo empréstimos por duplicatas descontadas e/ou notas promissórias, inclusive a } \\
\text { avaliação dos riscos e benefícios financeiros envolvidos nas transações. }\end{array}$ \\
\hline
\end{tabular}

Fonte: Elaborada pelos autores. 
A aplicação de cada caso para ensino aconteceu em três momentos distintos: pré-aula, aula e pósaula. Como pré-aula, os estudantes tiveram que seguir as instruções e realizar as atividades disponibilizadas na plataforma Moodle: leitura das referências indicadas, quizzes e resolução dos casos para ensino. As técnicas de ensino GV-GO, Júri Simulado e PBL foram aplicadas no momento aula. Na Tabela 4, registrase uma síntese do processo de aplicação dessas técnicas.

Tabela 4

\section{Processo de aplicação das técnicas de ensino em sala de aula}

\begin{tabular}{|c|c|}
\hline Tema & Forma de aplicação da técnica para resolução do caso para ensino \\
\hline $\begin{array}{l}\text { Fundo Fixo e } \\
\text { Conciliação } \\
\text { Bancária }\end{array}$ & $\begin{array}{l}\text { GV-GO: sortearam-se seis duplas para apresentarem a conciliação bancária. Posteriormente, os } \\
\text { estudantes foram divididos em grupo verbalizador e observador para o debate sobre a gestão das } \\
\text { disponibilidades e sobre o controle interno. Após essa etapa, os papéis dos grupos foram invertidos. } \\
\text { Ao final, as tutoras fizeram suas complementações para encerramento da técnica. }\end{array}$ \\
\hline $\begin{array}{l}\text { Provisões } \\
\text { e Passivos } \\
\text { Contingentes }\end{array}$ & $\begin{array}{l}\text { Júri Simulado: os estudantes foram divididos em: grupo de acusação, grupo de defesa, júri e juiz. } \\
\text { Cada grupo tinha um tempo delimitado para fazer suas argumentações. Após os debates entre os } \\
\text { grupos, o docente realizou o fechamento apontando os pontos principais sobre o tema. }\end{array}$ \\
\hline $\begin{array}{l}\text { Duplicatas } \\
\text { em Carteira, } \\
\text { Cobrança } \\
\text { Simples e } \\
\text { Desconto de } \\
\text { Duplicatas }\end{array}$ & $\begin{array}{l}\text { PBL: a aplicação da técnica foi segregada em sete etapas e desenvolvida em duas sessões tutoriais. } \\
\text { Na primeira sessão, os discentes foram separados em grupos e receberam instruções para } \\
\text { escolherem um líder e um secretário para assessorar o grupo, bem como realizarem as etapas um a } \\
\text { cinco: i) leitura da situação-problema; ii) identificação de problemas; iii) discussão dos conhecimentos } \\
\text { prévios; iv) síntese das etapas anteriores; e v) identificação dos assuntos/temas a serem estudados. } \\
\text { Posteriormente, os tutores discutiram cada etapa com os estudantes e solicitaram a entrega dos } \\
\text { relatórios elaborados em grupo. Como pós-aula, os discentes foram orientados a entregar um novo } \\
\text { relatório com todas as etapas refeitas, e realizar individualmente a etapa seis: busca de informações. } \\
\text { Na segunda sessão tutorial, os grupos anteriores foram mantidos. A última etapa do PBL - etapa } \\
\text { sete: integração das informações e resolução dos problemas, propôs que os estudantes elaborassem } \\
\text { um relatório final com informações úteis para a resolução da situação-problema identificada. Para } \\
\text { a discussão do caso para ensino, foram distribuídas aleatoriamente para os grupos as seguintes } \\
\text { atividades: apresentação; elaboração de perguntas; respostas às perguntas; e complementação } \\
\text { de respostas. Por fim, os tutores realizaram o fechamento da técnica, e solicitaram a entrega do } \\
\text { relatório final pelos grupos. }\end{array}$ \\
\hline
\end{tabular}

Fonte: elaborada pelos autores.

Após a aplicação das técnicas de ensino no momento aula (Tabela 4), na pós-aula os discentes deram continuidade ao estudo de cada tema com as atividades propostas, com o objetivo de consolidação e verificação da aprendizagem.

\subsection{Aplicação do questionário e realização do Grupo Focal}

Para identificar a percepção dos estudantes sobre o desenvolvimento de habilidades e competências na aplicação das técnicas de ensino, utilizou-se um questionário baseado em Weil, Oyelere, Yeoh e Firer (2001) e adaptado por Costa et al. (2018) para estabelecer uma relação com os domínios cognitivo e afetivo da TB. Este instrumento compreende quatro partes: i) informações para caracterização do respondente: idade, período regular, gênero, ocupação e se atuavam na área contábil; ii) avaliação das técnicas, contendo 37 afirmações para os estudantes atribuírem nota (de um adez) sobre uma provável aquisição de competências; iii) quatro afirmações para os estudantes atribuírem nota (de um a dez) sobre: benefícios, utilidade e formas de aplicação das técnicas; e iv) questões abertas - espaço para os discentes exporem livremente suas opiniões. 
A disciplina Contabilidade Introdutória II foi ministrada no segundo semestre letivo de 2019, primeiro ano de graduação em Ciências Contábeis. Do total de 48 discentes matriculados, 37 cursavam a disciplina pela primeira vez. Participaram da aplicação da técnica GV-GO 31 estudantes; do Júri Simulado, 23 estudantes; e 33 discentes do PBL, somando 87 respostas. Os estudantes responderam, voluntariamente, aos questionários de avaliação ao final da aplicação de cada técnica de ensino. A faixa etária dos respondentes situou-se entre 18 e 40 anos, com a idade média de 20 anos, sendo 51\% do sexo masculino. Quanto ao exercício da profissão contábil, $71 \%$ dos estudantes informaram não trabalhar e $12 \%$ dos que trabalhavam disseram atuar na área contábil.

As respostas fornecidas pelos estudantes foram analisadas com o auxílio da estatística descritiva. $\mathrm{Na}$ sequência, o teste de normalidade univariado de Shapiro-Francia foi utilizado para avaliar a aplicabilidade de testes paramétricos e não paramétricos aos respectivos dados (Fávero, Belfiore, Silva, \& Chan, 2009). Para os outputs que seguiram uma distribuição normal, empregou-se o teste $t$ de student para comparação de médias;para os demais, utilizou-se o teste de Kruskal-Wallis e de Wilcoxon para medianas. Esses procedimentos foram adotados para verificar se as habilidades e competências diferiram-se em relação às técnicas de ensino empregadas, os estágios do EEEC à luz da TB, bem como para avaliar a percepção geral dos estudantes quanto às metodologias ativas aplicadas.

Com o intuito de triangular a análise dos dados deste estudo, foi organizado um grupo focal com a participação de 12 estudantes. A duração foi de, aproximadamente, duas horas, nas dependências da universidade. Os estudantes aceitaram participar voluntariamente, e o critério para escolhê-los balanceou características como gênero (cinco homens e seis mulheres) e desempenho da disciplina (menores e maiores notas.)

O grupo focal foi conduzido por um moderador e por três observadores. Como no estudo de Costa et al. (2020), os temas presentes no roteiro de discussão foram: i) desenvolvimento de habilidades e competências em cada etapa do trabalho (caso e técnicas de aplicação); ii) motivação; iii) estudo e pesquisa individual ou em grupo; iv) visão empresarial prática; v) trabalho em equipe; (vi) dificuldades e limitações; e vii) desempenho na disciplina. Caso o debate não se desenvolvesse a partir da pergunta principal de cada um desses tópicos, o moderador dispunha de perguntas alternativas para buscar a participação dos estudantes.

Antes de iniciar o grupo focal, o moderador esclareceu aos participantes que as notas da disciplina Contabilidade Introdutória II haviam sido fechadas, embora ainda não divulgadas. O grupo focal foi gravado com recursos audiovisuais (após autorização formal dos estudantes), tendo a sua transcrição na íntegra sido feita manualmente pelos observadores. Assim como realizado no estudo de Cunha, Beuren, \& Guerreiro (2014), a análise do conteúdo teve como referência as respostas e perguntas do roteiro da discussão. Para citar as conversas dos participantes no grupo focal, seus nomes foram substituídos por A1, A2 (...) A12.

\section{Análise dos Resultados}

Na Tabela 5, têm-se uma média geral para as três técnicas e também a percepção dos estudantes para cada uma delas. Primeiramente, foi feita uma análise da média geral da percepção dos estudantes (Tabela 5, coluna "Geral"). Com base no ranking elaborado a partir da média geral das notas obtidas no questionário, a percepção dos estudantes mostra que os casos para ensino aplicados com as técnicas de ensino GV-GO, Júri Simulado e PBL possibilitaram o desenvolvimento das 37 habilidades e competências ligadas aos domínios cognitivo e afetivo da TB (média geral entre 7,56 e 8,88), corroborando Coetzee e Schmuliam (2013), por considerarem que a mudança no estilo tradicional de ensino acarreta o desenvolvimento de habilidades e competências pelos estudantes. 
A competência de "visão prática do processo de tomada de decisões" ocupou a $1^{\text {a }}$ posição do ranking (média de 8,88, Tabela 5). Essa competência também ficou no $1^{\circ}$ lugar do ranking no estudo de Costa et al. (2020), e em $2^{\circ}$ lugar do ranking no estudo de Costa et al. (2018). Esse resultado sugere que a utilização de metodologias ativas pode auxiliar os estudantes a visualizar o ambiente empresarial e o processo de tomada de decisões, o que é relevante para a formação profissional conforme preconiza a AICPA (2020).

A $2^{\text {a }}$ posição no ranking é "responsabilidade pelo próprio aprendizado" tanto neste estudo quanto no de Costa et al. (2020), e o $7^{\circ}$ lugar no estudo de Costa et al. (2018). No grupo focal, essa competência foi comentada pela estudante A12: "tivemos que ir atrás das informações, ir atrás do conhecimento, antes de fornecerem para a gente". Para a estudante A4, essa competência foi mais desenvolvida com a técnica PBL: "o PBL instigou mais a questão de procurar, ir atrás do conhecimento, estimular a pesquisa (...), no $P B L$ a gente teve que ir atrás de tudo antes". Por essa competência pertencer ao domínio afetivo da TB, essas constatações evidenciam que os estudantes se envolveram afetivamente com as metodologias ativas aplicadas, e que essa competência pode auxiliar o desenvolvimento do nível cognitivo dos estudantes, de acordo com Bloom et al. (1974) e Costa et al. (2020).

A $3^{\text {a }}$ posição do ranking foi ocupada pela competência de "visão do funcionamento de uma empresa", enquanto no estudo de Costa et al. (2020) e de Costa et al. (2018) ocupou a $5^{\mathrm{a}}$ e a $16^{\mathrm{a}}$ posição, respectivamente (Tabela 5). Considerando o desenvolvimento dessa competência e mais a competência de "visão prática do processo de tomada de decisões" na $1^{a}$ posição do ranking, verifica-se que os casos aplicados com as técnicas de ensino GV-GO, Júri Simulado e PBL, de maneira geral, fizeram com que os estudantes vislumbrassem mais o ambiente empresarial do que com a técnica role-play empregada por Costa et al. (2020), e o caso para ensino OpenSafari aplicado com a técnica PBL na pesquisa de Costa et al. (2018). Logo, as metodologias ativas aplicadas neste estudo estimularam, principalmente, o desenvolvimento das competências relacionadas aos negócios, e recomendadas pela AICPA (2020), conduzindo os estudantes a compreenderem fatores ligados ao ambiente interno e externo das empresas (AICPA, 2020; Ott, Cunha, Júnior \& Luca, 2011).

Nesse sentido, o estudante A8 disse, no grupo focal, que as metodologias ativas aplicadas possibilitaram o seu amadurecimento por causa do contato com a prática: "acho que me ajudou na questão de amadurecer, porque a gente estuda a matéria na sala de aula e é isso. Aí quando você sai dessa 'caixinha', às vezes, fica meio confuso, mas também ajuda você ver a realidade e os problemas que ela tem, erros que os contadores não deveriam cometer; a gente aprende com os erros deles para não os repetir". A estudante A1 também compartilhou desta opinião: "dentro da faculdade, a gente fica muito preso na teoria, e quando a gente tem contato com estes casos, eu acho que a gente vai mais para a realidade".

Não obstante, em comparação com os estudos de Costa et al. (2020) e de Costa et al. (2018), as metodologias ativas aplicadas nesta pesquisa resultaram em posições superiores no ranking quanto às seguintes habilidades e competências: "conhecimento técnico" (4a posição versus $11^{\text {a }} \mathrm{em}$ ambos os

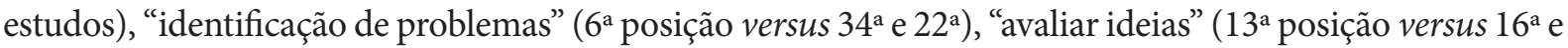
$15^{a}$ ), "síntese" (15 posição versus $29^{a}$ e $25^{a}$ ) e "organização de informações" (19a versus $23^{a}$ e $20^{a}$ ). Portanto, essas habilidades e competências foram mais percebidas pelos estudantes na aplicação de casos com as técnicas de ensino GV-GO, Júri Simulado e PBL, sugerindo que a hipótese $\mathrm{H}_{1}$ não pode ser rejeitada. 
Tabela 5

\section{Ranking das habilidades e competências}

\begin{tabular}{|c|c|c|c|c|c|c|c|c|c|c|c|c|c|c|c|c|}
\hline \multirow{2}{*}{$\mathbf{R}$} & \multirow{2}{*}{$\begin{array}{l}\text { Habilidades e } \\
\text { Competências }\end{array}$} & \multirow{2}{*}{ TB } & \multicolumn{2}{|c|}{ Geral } & \multicolumn{4}{|c|}{ GV-GO } & \multicolumn{4}{|c|}{ Júri Simulado } & \multicolumn{4}{|c|}{ PBL } \\
\hline & & & $\bar{x}$ & $M$ & $\bar{x}$ & $M$ & $P>t$ & $P>z$ & $\bar{x}$ & $M$ & $\mathrm{P}>\mathrm{t}$ & $\mathrm{P}>\mathrm{Z}$ & $\bar{x}$ & $M$ & $\mathrm{P}>\mathrm{t}$ & $\mathrm{P}>\mathrm{Z}$ \\
\hline 1 & $\begin{array}{l}\text { Visão prática do } \\
\text { processo de tomada } \\
\text { de decisões }\end{array}$ & SÍNT & 8,88 & 9 & 8,77 & 9 & 0,58 & & 9,00 & 10 & & 0,77 & 8,91 & 9 & & 0,83 \\
\hline 2 & $\begin{array}{l}\text { Responsabilidade } \\
\text { pelo próprio } \\
\text { aprendizado }\end{array}$ & AFET & 8,83 & 9 & 8,63 & 9 & & 0,37 & 8,70 & 9 & & 0,56 & 9,09 & 10 & & 0,16 \\
\hline 3 & $\begin{array}{l}\text { Visão do } \\
\text { funcionamento de } \\
\text { uma empresa }\end{array}$ & SÍNT & 8,80 & 9 & 8,79 & 9 & & 0,94 & 8,78 & 9 & & 0,85 & 8,82 & 9 & & 0,92 \\
\hline 4 & $\begin{array}{l}\text { Conhecimento } \\
\text { técnico }\end{array}$ & COMP & 8,76 & 9 & 8,83 & 9 & & 0,91 & 8,70 & 9 & & 0,88 & 8,73 & 9 & & 0,98 \\
\hline 5 & $\begin{array}{l}\text { Considerar várias } \\
\text { soluções }\end{array}$ & AVAL & 8,70 & 9 & 8,93 & 10 & & 0,36 & 8,39 & 9 & & 0,25 & 8,70 & 9 & & 0,89 \\
\hline 6 & $\begin{array}{l}\text { Identificação de } \\
\text { problemas }\end{array}$ & $\mathrm{CONH}$ & 8,61 & 9 & 8,77 & 9 & & 0,64 & 8,71 & 9 & & 0,81 & 8,39 & 9 & 0,22 & \\
\hline 7 & $\begin{array}{l}\text { Relacionar teoria e } \\
\text { prática }\end{array}$ & síNT & 8,61 & 9 & 9,00 & 10 & & $0,05^{*}$ & 8,35 & 8 & & 0,25 & 8,42 & 9 & & 0,38 \\
\hline 8 & Interpretação & ANÁL & 8,53 & 9 & 8,94 & 9 & & $0,05 *$ & 8,39 & 8 & & 0,44 & 8,24 & 8 & & 0,21 \\
\hline 9 & $\begin{array}{l}\text { Considerar } \\
\text { diferentes } \\
\text { perspectivas e } \\
\text { usuários }\end{array}$ & SÍNT & 8,53 & 9 & 8,65 & 9 & & 0,73 & 8,70 & 9 & & 0,42 & 8,30 & 8 & & 0,29 \\
\hline 10 & $\begin{array}{l}\text { Pensar } \\
\text { conceitualmente }\end{array}$ & ANÁL & 8,51 & 9 & 8,55 & 8 & & 0,92 & 8,48 & 9 & & 0,78 & 8,48 & 9 & 0,92 & \\
\hline 11 & $\begin{array}{l}\text { Integração de } \\
\text { diversos assuntos } \\
\text { da disciplina }\end{array}$ & COMP & 8,49 & 9 & 8,61 & 9 & & 0,45 & 8,13 & 8 & & 0,08 & 8,64 & 9 & & 0,40 \\
\hline 12 & $\begin{array}{l}\text { Aplicação do } \\
\text { conhecimento }\end{array}$ & SÍNT & 8,49 & 9 & 8,74 & 9 & & 0,28 & 8,57 & 9 & & 0,89 & 8,21 & 8 & & 0,23 \\
\hline 13 & Avaliar ideias & ANÁL & 8,48 & 9 & 8,58 & 9 & 0,71 & & 8,91 & 9 & & 0,58 & 8,09 & 9 & & 0,12 \\
\hline 14 & Pensamento crítico & ANÁL & 8,42 & 8 & 8,66 & 9 & 0,32 & & 8,57 & 8 & & 0,91 & 8,09 & 8 & & $0,05^{*}$ \\
\hline 15 & Síntese & COMP & 8,41 & 8 & 8,65 & 9 & & 0,39 & 8,30 & 8 & & 0,56 & 8,27 & 8 & & 0,75 \\
\hline 16 & Análise & ANÁL & 8,41 & 9 & 8,44 & 9 & 0,92 & & 8,45 & 9 & & 0,85 & 8,36 & 9 & 0,83 & \\
\hline 17 & $\begin{array}{l}\text { Identificação de } \\
\text { dados relevantes }\end{array}$ & $\mathrm{CONH}$ & 8,38 & 8 & 8,23 & 8 & 0,55 & & 8,61 & 9 & & 0,53 & 8,36 & 9 & 0,95 & \\
\hline 18 & $\begin{array}{l}\text { Sumarizar } \\
\text { informações }\end{array}$ & COMP & 8,35 & 9 & 8,66 & 9 & & 0,19 & 8,39 & 9 & & 0,91 & 8,03 & 8 & & 0,23 \\
\hline 19 & $\begin{array}{l}\text { Organização de } \\
\text { informações }\end{array}$ & $\mathrm{CONH}$ & 8,34 & 8 & 8,42 & 9 & 0,77 & & 8,65 & 8 & & 0,51 & 8,06 & 8 & 0,23 & \\
\hline 20 & $\begin{array}{l}\text { Estudar os } \\
\text { conteúdos da } \\
\text { disciplina }\end{array}$ & AFET & 8,31 & 9 & 8,39 & 9 & 0,80 & & 8,50 & 9 & & 0,73 & 8,12 & 9 & & 0,86 \\
\hline 21 & $\begin{array}{l}\text { Interpretação das } \\
\text { demonstrações } \\
\text { financeiras }\end{array}$ & ANÁL & 8,26 & 9 & 8,08 & 8 & 0,53 & & 9,27 & 10 & & 0,00 * & 7,76 & 8 & 0,06 & \\
\hline 22 & $\begin{array}{l}\text { Consolidação de } \\
\text { conhecimentos } \\
\text { prévios }\end{array}$ & COMP & 8,25 & 9 & 8,87 & 10 & & $0,02 *$ & 8,04 & 8 & & 0,30 & 7,82 & 8 & & 0,17 \\
\hline
\end{tabular}




\begin{tabular}{|c|c|c|c|c|c|c|c|c|c|c|c|c|c|c|c|c|}
\hline \multirow{2}{*}{$\mathbf{R}$} & \multirow{2}{*}{$\begin{array}{l}\text { Habilidades e } \\
\text { Competências }\end{array}$} & \multirow{2}{*}{ TB } & \multicolumn{2}{|c|}{ Geral } & \multicolumn{4}{|c|}{ GV-GO } & \multicolumn{4}{|c|}{ Júri Simulado } & \multicolumn{4}{|c|}{ PBL } \\
\hline & & & $\overline{\bar{x}}$ & $M$ & $\overline{\bar{x}}$ & $M$ & $P>t$ & $\mathrm{P}>\mathrm{Z}$ & $\bar{x}$ & $M$ & $P>t$ & $P>Z$ & $\bar{x}$ & $M$ & $P>t$ & $P>Z$ \\
\hline 23 & $\begin{array}{l}\text { Resolução de } \\
\text { problemas }\end{array}$ & APLIC & 8,16 & 8 & 8,61 & 9 & & 0,08 & 7,87 & 8 & & 0,19 & 7,94 & 8 & & 0,57 \\
\hline 24 & $\begin{array}{l}\text { Distinguir fatos de } \\
\text { opiniões }\end{array}$ & APLIC & 8,15 & 8 & 8,06 & 8 & & 0,79 & 8,70 & 9 & & 0,16 & 7,85 & 8 & & 0,31 \\
\hline 25 & Participação ativa & AFET & 8,12 & 8 & 8,1 & 8 & 0,95 & & 8,30 & 8 & & 0,82 & 8,03 & 8 & & 0,85 \\
\hline 26 & $\begin{array}{l}\text { Habilidades de } \\
\text { pesquisa }\end{array}$ & AFET & 8,10 & 8 & 8,31 & 9 & & 0,47 & 8,41 & 9 & & 0,46 & 7,70 & 8 & & 0,17 \\
\hline 27 & $\begin{array}{l}\text { Lidar com incerteza } \\
\text { e ambiguidade }\end{array}$ & AVAL & 8,09 & 8 & 8,26 & 8 & & 0,87 & 7,87 & 8 & 0,54 & & 8,09 & 9 & 1,00 & \\
\hline 28 & Julgamento & APLIC & 8,09 & 8 & 8,11 & 8 & 0,93 & & 8,65 & 9 & & 0,11 & 7,67 & 8 & 0,13 & \\
\hline 29 & $\begin{array}{l}\text { Questionamentos } \\
\text { pertinentes }\end{array}$ & AFET & 8,07 & 8 & 8,08 & 9 & & 0,86 & 8,39 & 9 & & 0,26 & 7,85 & 8 & & 0,23 \\
\hline 30 & $\begin{array}{l}\text { Tomada de decisões } \\
\text { com informações } \\
\text { incompletas }\end{array}$ & AVAL & 8,06 & 9 & 7,90 & 8 & 0,63 & & 8,30 & 9 & 0,53 & & 8,03 & 9 & 0,93 & \\
\hline 31 & Trabalho em equipe & $\mathrm{CONH}$ & 8,02 & 8 & 7,38 & 8 & $0,04 *$ & & 8,35 & 8 & & 0,73 & 8,36 & 9 & 0,23 & \\
\hline 32 & Persuasão & $\mathrm{CONH}$ & 7,98 & 8 & 7,94 & 9 & 0,89 & & 8,52 & 9 & & 0,20 & 7,63 & 8 & & 0,09 \\
\hline 33 & Habilidade de ouvir & $\mathrm{CONH}$ & 7,95 & 8 & 7,85 & 8 & & 0,66 & 8,43 & 8 & & 0,32 & 7,70 & 8 & 0,35 & \\
\hline 34 & Motivação & AFET & 7,85 & 9 & 7,68 & 9 & 0,64 & & 8,30 & 9 & & 0,56 & 7,70 & 9 & 0,66 & \\
\hline 35 & $\begin{array}{l}\text { Oratória e } \\
\text { comunicação verbal }\end{array}$ & $\mathrm{CONH}$ & 7,69 & 8 & 7,5 & 8 & 0,59 & & 8,36 & 9 & 0,13 & & 7,41 & 8 & 0,40 & \\
\hline 36 & Criatividade & AFET & 7,61 & 8 & 7,34 & 8 & 0,39 & & 8,45 & 9 & $0,04^{*}$ & & 7,30 & 7 & & 0,07 \\
\hline 37 & $\begin{array}{l}\text { Comunicação } \\
\text { escrita }\end{array}$ & $\mathrm{CONH}$ & 7,56 & 8 & 7,58 & 8 & 0,95 & & 7,61 & 8 & & 0,87 & 7,52 & 8 & 0,72 & \\
\hline
\end{tabular}

Nota: R: ranking das habilidades e competências escolhidas pelos estudantes de acordo com a média geral; TB:

Taxonomia de Bloom; AFET: domínio afetivo; APLIC: aplicação; ANÁL: análise; AVAL: avaliação; COMP: compreensão; CONH: conhecimento; SÍNT: síntese; $\bar{x}$ : média; M: mediana; P>t: p-valor do teste $t$ de student entre a média das habilidades e competências em cada técnica de ensino e as demais; $P>z$ : $p$-valor do teste de Kruskal-Wallis entre a mediana das habilidades e competências em cada técnica de ensino e as demais; N: n. ${ }^{\circ}$ de observações; *: variáveis distintas estatisticamente.

Fonte: elaborada pelos autores.

Especificamente, considerando o caso aplicado com a técnica de ensino GV-GO, tem-se que os estudantes perceberam maior desenvolvimento das habilidades e competências de "relacionar teoria e prática", "interpretação" e "consolidação de conhecimentos prévios". Acerca da habilidade de "relacionar teoria e prática", alguns estudantes enfatizaram, no grupo focal, que a metodologia aplicada possibilitou visualizar a contabilidade na prática: "pareceu mais próximo da realidade" (A9). "Acho que a gente sentiu mais a profissão" (A7). Associada com as habilidades de "interpretação" e "consolidação de conhecimentos prévios", a estudante A11 disse: "o GV-GO foi o que fez a gente trabalhar mais, porque lutamos para entender conciliação bancária, perguntava no grupo o que é cheque compensando, o que é isso, o que é aquilo". A estudante A6 concluiu: "todas as etapas do GV-GO, desde solucionar o Caso do Sindicato, de ouvir, falar e saber debater, o GV-GO foi o que mais fez a gente se sentir um contador" (A6). Em oposição às demais metodologias ativas aplicadas, a habilidade de "trabalho em equipe" apresentou menor desenvolvimento com o caso aplicado com a técnica de ensino GV-GO (média de 7,38). Esse achado corrobora as habilidades e competências elencadas na Tabela 2, visto que seu desenvolvimento não é contemplado na literatura com a aplicação da técnica de ensino GV-GO. 
A respeito do caso aplicado com a técnica de ensino Júri Simulado, verifica-se, na Tabela 5, que os estudantes perceberam maior desenvolvimento da habilidade de "interpretação das demonstrações financeiras" e da competência de "criatividade". Em função de aludira situações ocorridas no contexto brasileiro sobre identificação, mensuração e reconhecimento de provisões, passivos e ativos contingentes, a habilidade de "interpretação das demonstrações financeiras" pode ter sido escolhida pelos discentes como alternativa para a habilidade de argumentação prevista na Tabela 2 , conforme se verifica nas falas dos estudantes no grupo focal: "no Júri tem isso de argumentar, mesmo não concordando com o que está acontecendo" (A2). "A atividade de Júri traz muito mais argumentação do que a do PBL" (A12). "Eu concordo com A12, eu acho que o Júri e o GV-GO instigam mais a parte de argumentação" (A4).

Sobre o desenvolvimento da competência de "criatividade" com a técnica Júri Simulado, esta pode ter sido vislumbrada pelos estudantes por se relacionar com a habilidade de argumentação, conforme salientaram as estudantes A1 e A4 no grupo focal: "no momento em que estamos num júri, a gente tem que conseguir criar um argumento muito rápido" (A1); "eu acho que também no júri talvez a gente perde um pouco do foco, porque eu lembro das vezes que a (...) tinha que chegar na gente e falar: não esqueçam que o foco é provisão! Você fica tão instigado em querer argumentar sobre aquilo que esquece de fato (...)" (A4). Embora a estudante A4 tenha comentado sobre a perda de foco da discussão durante o momento de acusação e de defesa com esta técnica, sua fala fornece indícios de que os estudantes buscaram ser criativos. Este achado demonstra que essa técnica pode ser considerada pelo docente, quando o objetivo educacional for o desenvolvimento da habilidade de criatividade, além de compor o conjunto de habilidades e competências indicados pela literatura (Tabela 2).

No que refere ao caso aplicado com a técnica de ensino PBL, verifica-se, na Tabela 5, que a habilidade de "pensamento crítico" foi menos desenvolvida com essa técnica, em comparação com as demais, segundo a percepção dos estudantes, apesar da média de 8,09. O desenvolvimento desta habilidade e confirma Soares et al. (2017), no sentido de valer-se da técnica de ensino PBL para direcionar o estudante para um conhecimento mais profundo, além de favorecer o desenvolvimento de outras habilidades e competências (Tabela 2). No grupo focal, os estudantes salientaram que a técnica possibilitou que interligassem assuntos de outras disciplinas ou exercitassem a habilidade de pesquisa.

Destarte, as habilidades e competências desenvolvidas em cada caso aplicado com as técnicas de ensino não permitem rejeitar a hipótese um da pesquisa $\left(\mathrm{H}_{1}\right)$, sugerindo que a aplicação das técnicas de ensino GV-GO, Júri Simulado e PBL na resolução de casos para ensino, desenvolve habilidades e competências distintas, de acordo com a percepção dos estudantes. Infere-se, pelo já exposto neste trabalho, que as 37 habilidades e competências constantes do ranking foram desenvolvidas na visão dos estudantes, sobretudo, em razão das notas médias obtidas serem maiores que sete. Além disso, dentre as técnicas de ensino aplicadas, quatro foram mais percebidas com a GV-GO, duas com a Júri Simulado e uma com a PBL.

Na Tabela 6, é registrada a estatística descritiva para os domínios da TB, bem como os testes de hipóteses realizados para avaliar se as habilidades e competências indicadas pelos estudantes diferem entre os estágios do EEEC. 
Tabela 6

Comparação entre os domínios investigados da TB e os estágios do EEEC

\begin{tabular}{|c|c|c|c|c|c|c|c|c|c|}
\hline \multicolumn{10}{|c|}{ Painel A - Geral } \\
\hline TB & $\mathrm{N}$ & $\bar{x}$ & s & Mín & M & Máx & \multicolumn{3}{|c|}{ Estágios do EEEC } \\
\hline Domínio Afetivo & 83 & 8,16 & 1,36 & 4 & 8,29 & 10 & E1 & E2 & E3 \\
\hline Conhecimento & 82 & 8,08 & 1,3 & 2,63 & 8,19 & 10 & \multirow{3}{*}{$\begin{array}{l}\bar{x}: 8,24 \\
M: 8,32\end{array}$} & \multirow{6}{*}{$\begin{array}{c}\bar{x}: 8,29 \\
\mathrm{M}: 8,35 \\
\mathrm{P}>\mathrm{z}: 0,00^{* a}\end{array}$} & \multirow{6}{*}{$\begin{array}{c}\bar{x}: 8,35 \\
\mathrm{M}: 8,37 \\
\mathrm{P}>\mathrm{z}: 0,00 \text { *b }\end{array}$} \\
\hline Compreensão & 86 & 8,45 & 1,13 & 3,4 & 8,4 & 10 & & & \\
\hline Aplicação & 87 & 8,13 & 1,46 & 1,33 & 8,33 & 10 & & & \\
\hline Análise & 84 & 8,42 & 1,2 & 3 & 8,5 & 10 & & & \\
\hline Síntese & 86 & 8,66 & 1,02 & 5,6 & 8,7 & 10 & & & \\
\hline Avaliação & 86 & 8,29 & 1,37 & 3,33 & 8,33 & 10 & & & \\
\hline \multicolumn{10}{|c|}{ Painel B - GV-GO } \\
\hline TB & $\mathrm{N}$ & $\bar{x}$ & s & Mín & M & Máx & \multicolumn{3}{|c|}{ Estágios do EEEC } \\
\hline Domínio Afetivo & 30 & 8,2 & 1,43 & 5,43 & 8,71 & 10 & E1 & E2 & E3 \\
\hline Conhecimento & 30 & 8 & 1,3 & 5,13 & 8,31 & 10 & \multirow{3}{*}{$\begin{array}{l}\bar{x}: 8,36 \\
\mathrm{M}: 8,48\end{array}$} & \multirow{4}{*}{$\begin{array}{c}\bar{x}: 8,42 \\
\mathrm{M}: 8,63 \\
\mathrm{P}>\mathrm{z}: 0,01^{\text {*a }}\end{array}$} & \multirow{6}{*}{$\begin{array}{c}\bar{x}: 8,48 \\
\mathrm{M}: 8,62 \\
\mathrm{P}>\mathrm{z}: 0,03\end{array}$} \\
\hline Compreensão & 30 & 8,73 & 1,07 & 6,2 & 9,05 & 10 & & & \\
\hline Aplicação & 31 & 8,26 & 1,4 & 4 & 8,33 & 10 & & & \\
\hline Análise & 31 & 8,54 & 1,26 & 4,67 & 9 & 10 & & & \\
\hline Síntese & 31 & 8,79 & 1 & 7 & 8,8 & 10 & & & \\
\hline Avaliação & 30 & 8,4 & 1,3 & 4,33 & 8,33 & 10 & & & \\
\hline \multicolumn{10}{|c|}{ Painel C - Júri Simulado } \\
\hline TB & $\mathrm{N}$ & $\bar{x}$ & s & Mín & M & Máx & \multicolumn{3}{|c|}{ Estágios do EEEC } \\
\hline Domínio Afetivo & 20 & 8,41 & 1,07 & 5,57 & 8,5 & 10 & E1 & E2 & E3 \\
\hline Conhecimento & 21 & 8,4 & 0,85 & 7 & 8,75 & 10 & \multirow{3}{*}{$\begin{array}{l}\bar{x}: 8,35 \\
\mathrm{M}: 8,33\end{array}$} & \multirow{4}{*}{$\begin{array}{c}\bar{x}: 8,41 \\
\mathrm{M}: 8,34 \\
\mathrm{P}>\mathrm{z}: 0,01 \text { *a }\end{array}$} & \multirow{6}{*}{$\begin{array}{c}\bar{x}: 8,39 \\
\text { M: 8,35 } \\
\text { P>z: } 0,32^{b}\end{array}$} \\
\hline Compreensão & 23 & 8,31 & 0,79 & 6,8 & 8,2 & 10 & & & \\
\hline Aplicação & 23 & 8,41 & 0,86 & 7,33 & 8,33 & 10 & & & \\
\hline Análise & 20 & 8,65 & 0,63 & 7,5 & 8,5 & 10 & & & \\
\hline Síntese & 22 & 8,68 & 1 & 6,4 & 8,7 & 10 & & & \\
\hline Avaliação & 23 & 8,19 & 1,18 & 5,67 & 8,33 & 10 & & & \\
\hline \multicolumn{10}{|c|}{ Painel D - PBL } \\
\hline TB & $\mathrm{N}$ & $\bar{x}$ & s & Mín & M & Máx & \multicolumn{3}{|c|}{ Estágios do EEEC } \\
\hline Domínio Afetivo & 33 & 7,97 & 1,46 & 4 & 8,14 & 10 & E1 & E2 & E3 \\
\hline Conhecimento & 31 & 7,95 & 1,52 & 2,63 & 8 & 10 & \multirow{3}{*}{$\begin{array}{l}\bar{x}: 8,04 \\
\mathrm{M}: 8,02\end{array}$} & \multirow{4}{*}{$\begin{array}{c}\bar{x}: 8,08 \\
\mathrm{M}: 8,14 \\
\mathrm{P}>\mathrm{z}: 0,02^{\text {*a }}\end{array}$} & \multirow{6}{*}{$\begin{array}{c}\bar{x}: 8,21 \\
\mathrm{M}: 8,27 \\
\mathrm{P}>\mathrm{z}: 0,00\end{array}$} \\
\hline Compreensão & 33 & 8,3 & 1,34 & 3,4 & 8,4 & 10 & & & \\
\hline Aplicação & 33 & 7,82 & 1,78 & 1,33 & 7,67 & 10 & & & \\
\hline Análise & 33 & 8,17 & 1,38 & 3 & 8,33 & 10 & & & \\
\hline Síntese & 33 & 8,53 & 1,06 & 5,6 & 8,6 & 10 & & & \\
\hline Avaliação & 33 & 8,27 & 1,58 & 3,33 & 8,67 & 10 & & & \\
\hline
\end{tabular}

Nota: TB: Taxonomia de Bloom; N: n. ${ }^{\circ}$ de observações; $\bar{x}$ : média; s: desvio padrão; Mín: valor mínimo; M: mediana; Máx: valor máximo; E1, E2 e E3: média das categorias do domínio cognitivo da TB que compõem os estágios 1, 2 e 3 do EEEC (conforme Tabela 1); P>z: p-valor do teste de Wilcoxon entre: 1) a:E1 e o E2; 2) b: E1 e o E3;*: variáveis distintas estatisticamente.

Fonte: elaborada pelos autores. 
As médias registradas na Tabela 6 (todas acima de 7,82) apontam que, na percepção dos estudantes, as habilidades e competências dos domínios afetivo e cognitivo da TB, bem como dos estágios 1, 2 e 3 do EEEC, foram desenvolvidas com a aplicação das técnicas GV-GO, Júri e PBL. Os testes de Wilcoxon $(\mathrm{P}>\mathrm{z})$ mostram que, de maneira geral, o estágio 1 se desenvolveu de maneira diferente dos estágios 2 (média de 8,29 , p-valor 0,00 ) e 3 (média de 8,35 , p-valor 0,00 ). O mesmo ocorreu com a aplicação das técnicas GVGO e PBL. Especificamente, as técnicas GV-GO e PBL desenvolveram mais habilidades e competências do estágio 3, seguidas dos estágios 2 e 1, respectivamente. Por outro lado, a técnica Júri desenvolveu mais as habilidades e competências do estágio 2 e, empatadas em segundo lugar estão aquelas dos estágios 1 e 3 .

Esses resultados corroboram os achados de Costa et al. (2018) e de Costa et al. (2020), uma vez que as metodologias ativas aplicadas nesta pesquisa permitiram o desenvolvimento de competências elencadas nas categorias simples para categorias mais complexas do domínio cognitivo da TB, que, por associação, correspondem aos estágios 1, 2 e 3 do EEEC, reforçando o argumento de que habilidades e competências do estágio intermediário e avançado podem ser desenvolvidas também no estágio inicial do EEEC. Tais constatações não permitem rejeitar a hipótese dois da pesquisa $\left(\mathrm{H}_{2}\right)$, sugerindo que a aplicação das técnicas de ensino GV-GO, Júri Simulado e PBL na resolução de casos para ensino, desenvolve de maneira diferente os estágios do EEEC.

Na Tabela 7, têm-se os outputs dos testes de hipóteses quanto à percepção geral dos estudantes sobre as metodologias ativas aplicadas.

Tabela 7

Percepção geral das metodologias ativas aplicadas

\begin{tabular}{|c|c|c|c|c|c|c|c|c|c|c|c|}
\hline \multirow{2}{*}{ Atributos } & \multicolumn{2}{|c|}{ Geral } & \multicolumn{3}{|c|}{ GV-GO } & \multicolumn{3}{|c|}{ Júri Simulado } & \multicolumn{3}{|c|}{ PBL } \\
\hline & $\bar{x}$ & $\mathbf{M}$ & $\bar{x}$ & M & $\mathrm{P}>\mathrm{t}$ & $\bar{x}$ & $\mathbf{M}$ & $\mathrm{P}>\mathrm{t}$ & $\bar{x}$ & M & $P>t$ \\
\hline Utilidade do caso para ensino & 9,24 & 10 & 9,24 & 10 & 0,12 & 9,30 & 10 & 0,14 & 8,36 & 8 & $0,00 *$ \\
\hline Utilidade da técnica de ensino & 8,92 & 9 & 8,92 & 9 & 0,73 & 9,43 & 10 & $0,02 *$ & 8,36 & 9 & $0,02 *$ \\
\hline $\begin{array}{l}\text { Melhora no processo de ensino- } \\
\text { aprendizagem }\end{array}$ & 8,61 & 10 & 8,61 & 10 & 0,91 & 9,22 & 10 & 0,07 & 8,27 & 9 & 0,13 \\
\hline $\begin{array}{l}\text { Adequação à disciplina de } \\
\text { Contabilidade Introdutória II }\end{array}$ & 9,61 & 10 & 9,61 & 10 & $0,05 *$ & 9,73 & 10 & $0,05 *$ & 8,33 & 9 & $0,00 *$ \\
\hline
\end{tabular}

Nota: $\bar{x}$ : média; M: mediana; P>t: $\mathrm{p}$-valor do teste $t$ de student entre cada atributo investigado nas metodologias aplicadas e as demais; ${ }^{*}$ variáveis distintas estatisticamente.

Fonte: elaborada pelos autores.

Os resultados sobre os atributos investigados na Tabela 7 mostram que os estudantes perceberam, de maneira geral, a utilidade e adequação dos casos aplicados com as técnicas de ensino GV-GO, Júri Simulado e PBL para a disciplina de Contabilidade Introdutória II, melhorando, assim, o processo de ensino-aprendizagem. Essa percepção dos estudantes confirma o desenvolvimento de habilidades e competências a partir do alinhamento entre os objetivos pedagógicos estabelecidos pelo docente e a utilização de metodologias ativas, conforme sugere Nagib e Silva (2020). 
Dentre as técnicas de ensino aplicadas, os estudantes perceberam menor utilidade tanto do caso quanto da técnica de ensino PBL aplicados, apesar de esta metodologia ter possibilitado o desenvolvimento de todas as habilidades e competências investigadas (Tabela 5). No grupo focal, as falas das estudantes auxiliam a compreender as razões desses resultados. De acordo com a estudante A7, uma das principais razões foi a escolha do conteúdo para o caso: "a única coisa que eu tenho para sugerir é sobre o PBL, para não aplicá-lo novamente com duplicatas, porque eu acho que é uma matéria com muitos detalhes". Para as estudantes A2 e A11, respectivamente, o motivo foi a ausência de elementos para realizar a contabilização: "eu achei legal, só que a empresa está adquirindo muitas duplicatas, então, como ela poderia resolver isso? A gente mostrar, por exemplo, em forma de lançamentos" (A2). "A gente acabou fugindo e não focou em nota promissória e duplicatas, além de não ter contato com os detalhes que são muitos" (A11). Apesar desses apontamentos, a expressividade da nota atribuída para a técnica de ensino PBL (média entre 8,27 e 8,36) salienta sua importância para o desenvolvimento de habilidades e competências pelos estudantes na disciplina. Como técnica de ensino com maior utilidade, os estudantes escolheram a Júri Simulado, o que, conforme já exposto neste trabalho, pode ter sido resultado da associação com a habilidade de "interpretação das demonstrações financeiras" e da competência de "criatividade", constatadas como as mais desenvolvidas com a aplicação desta metodologia ativa (Tabela 5).

Isto posto, os resultados da Tabela 7 evidenciam que as metodologias ativas aplicadas nesta pesquisa influenciaram o processo de ensino-aprendizagem na disciplina, ao permitirem que os estudantes desenvolvessem as 37 habilidades e competências constantes do ranking na Tabela 5, além dos domínios cognitivo e afetivo, e o alcance dos estágios 1, 2 e 3 do EEEC, ambos expostos na Tabela 6.

\section{Considerações Finais}

O objetivo deste estudo foi identificar quais habilidades e competências são desenvolvidas na resolução de casos para ensino com a aplicação de técnicas de ensino diferentes. Esse objetivo foi alcançado à luz da TB e do EEEC, a partir da aplicação de um questionário ao término da aplicação das técnicas de ensino GV-GO, Júri Simulado e PBL, e complementado com um grupo focal ao final da disciplina de Contabilidade Introdutória II.

Na visão dos estudantes, os casos para ensino aplicados com as três técnicas de ensino empregadas possibilitaram desenvolver todas as 37 habilidades e competências investigadas no questionário. Essas metodologias ativas permitiram que os estudantes visualizassem o ambiente empresarial e o processo de tomada de decisões. Além disso, os estudantes perceberam o desenvolvimento de sua autonomia e responsabilidade pelo próprio aprendizado, isso sugere que as metodologias fizeram com que os estudantes se envolvessem afetivamente com o processo de ensino-aprendizagem

Comparando os resultados da percepção dos estudantes para o desenvolvimento de habilidades e competências na utilização das três técnicas na aplicação dos casos para ensino, por meio de testes de média e mediana, tem-se que:

- a técnica GV-GO foi a que possibilitou maior desenvolvimento das habilidades e competências de "relacionar teoria e prática", "interpretação" e "consolidação de conhecimentos prévios". Por outro lado, a competência "trabalho em equipe" alcançou menor média na percepção dos estudantes;

- com a técnica Júri Simulado, o maior desenvolvimento foi constatado para as habilidades de "interpretação das demonstrações financeiras" e "criatividade";

- a técnica PBL se diferenciou das demais somente quanto à competência de "pensamento crítico", apontada pelos estudantes como menos desenvolvida (apesar da média de 8,09). 
Os resultados encontrados nesta pesquisa permitem concluir que a aplicação das técnicas de ensino GV-GO, Júri Simulado e PBL, na resolução de casos para ensino, desenvolve habilidades e competências distintas, de acordo com a percepção dos estudantes. Assim, infere-se que a escolha da técnica de ensino na aplicação de casos deve estar alinhada com os objetivos educacionais estabelecidos pelo docente.

Além disso, a aplicação das técnicas de ensino desenvolveu habilidades e competências de todos os estágios do EEEC e, consequentemente, dos domínios cognitivo e afetivo da TB, corroborando os estudos de Costa et al. (2018) e Costa et al. (2020). Assim, as metodologias ativas aplicadas são eficazes para o aprimoramento de habilidades e competências necessárias para a compreensão e a aplicação consistente das IFRS. As técnicas GV-GO e PBL desenvolveram na seguinte sequência os estágios do EEEC: 3, 2 e 1. Já com a aplicação do Júri Simulado, tem o estágio 2 em primeiro lugar e, empatados em segundo lugar, os estágios 1 e 3. Esses resultados sugerem que o Iasb poderia incluir na sua agenda o estudo de metodologias ativas adequadas para aplicação dos casos para ensino em cada um dos estágios do EEEC, uma vez que os resultados da pesquisa ressaltam a relevância da metodologia empregada na aplicação dos casos para ensino.

No mais, questões afetivas demonstradas pelos estudantes como interesse, responsabilidade pelo aprendizado, criatividade e participação ativa, contribuem para o desenvolvimento cognitivo, levando à constatação de que os domínios cognitivo e afetivo interagem entre si, alinhado com os resultados encontrados por Costa et al. (2020)

Como contribuições deste estudo ressalta-se a importância das técnicas de ensino para o desenvolvimento de habilidades e competências na resolução de casos para ensino, demonstrando com base nos achados da pesquisa que os objetivos educacionais de aprendizagem podem ser otimizados com o auxílio das metodologias ativas. Logo, esses resultados podem ser úteis aos docentes, às IES, aos gestores das empresas e aos órgãos reguladores que estão envolvidos no processo de ensino-aprendizagem das IFRS, para que seja fomentado o desenvolvimento de habilidades e competências requeridas para a formação do profissional da contabilidade. Especificamente o Iasb pode ir além do desenvolvimento de casos para ensino no EEEC, refletindo sobre quais metodologias utilizar na aplicação desses materiais.

Uma limitação do estudo pode estar relacionada com a impossibilidade de separar as habilidades e competências desenvolvidas exclusivamente com a resolução de casos para ensino e com as técnicas de ensino GV-GO, Júri Simulado e PBL. Nesse sentido, como sugestão para as pesquisas futuras sugere-se avaliar o desenvolvimento segregado e conjunto de habilidades e competências, utilizando as metodologias ativas aplicadas nesta pesquisa, bem como a interação com outras disciplinas.

\section{Referências}

AICPA (2020). American Institute of Certified Public Accountants. Recuperado em https://www.aicpa. org/InterestAreas/AccountingEducation/

Alberton, A., \& Silva, A. B. da. (2018). Como escrever um bom caso para ensino? Reflexões sobre o método. RAC - Revista de Administração Contemporânea, 22(6), pp. 745-761. Doi: 10.1590/19827849rac2018180212

Anastasiou, L. das G. C., \& Alves, L. P. (2004). (Org). Processos de ensinagem na universidade: pressupostos para as estratégias de trabalho em aula (3a ed.). Joinville: Univille.

Barth, M. E. (2008). Global financial reporting: Implications for U.S. academics. The Accounting Review, 83(5), pp. 1159-1179. Doi: 10.2308/accr.2008.83.5.1159

Berbel, N. A. N. (2011). As metodologias ativas e a promoção da autonomia de estudantes. Semina: Ciências Sociais e Humanas, 32(1), pp. 25-40. Doi: 10.5433/1679-0383.2011v32n1p25

Bloom, B. S., Engelhart, M. D., Furst, E. J., Hill, W. H., \& Krathwohl, D. R. (1983). Taxonomia de objetivos educacionais: Domínio cognitivo. 8a. ed. Porto Alegre, Rio de Janeiro: Globo. 
Bloom, B. S., Engelhart, M. D., Furst, E. J., Hill, W. H., \& Krathwohl, D. R. (1974). Taxonomia de objetivos educacionais: Domínio afetivo. Porto Alegre: Globo.

Carvalho, L. N., \& Salotti, B. M. (2013). Adoption of IFRS in Brazil and the consequences to accounting education. Issues in accounting education,28(2),pp. 235-242. Doi: 10.2308/iace-50373

Coetzee, S. A., \& Schmulian, A. (2013). The Effect of IFRS adoption on financial reporting pedagogy in South Africa. Issues in Accounting Education, 28(2), pp. 243-251. Doi: 10.2308/iace-50386

Costa, P. S., Ávila, J. R. M. S., Santos, D. V., \& Cruz, F. P. (2020). Role-play: desenvolvendo habilidades e competências do Ensino Embasado na Estrutura Conceitual. Revista de Contabilidade e Organizações, 14, pp. 2-15. Doi:10.11606/issn.1982-6486.rco.2020.164092

Costa, P. S., Gomes, G. S., Braunbeck, G. O., \& Santana, M. E. G. (2018). Um safari no Brasil: Evidências sobre o ensino baseado na estrutura conceitual. Revista Contabilidade \& Finanças, 29(76), pp. 129147. Doi: https://doi.org/10.1590/1808-057x201804760

Cunha, P. R., Beuren, I. M., \& Guerreiro, R. (2014). Fatores preditivos à desinstitucionalização de hábitos e rotinas na controladoria: Um estudo de caso. Contabilidade, Gestão e Governança, 17(2), pp. 60-77. Recuperado em: http://www.spell.org.br/documentos/ver/32654/fatores-preditivos-adesinstitucionalizacao-de-habitos-e-rotinas-na-controladoria--um-estudo-de-caso

Fávero, L. P. L., Belfiore, P. P., Silva, F. L. D., \& Chan, B. L. (2009). Análise de dados: modelagem multivariada para tomada de decisões. Rio de Janeiro: Elsevier.

Ferraz, A. P. C. M., \& Belhot, R. V. (2010). Taxonomia de Bloom: Revisão teórica e apresentação das adequações do instrumento para definição de objetivos instrucionais. Gestão \& Produção, 17(2), pp. 421-431. Doi: 10.1590/S0104-530X2010000200015

Gil, A. C. (2006). Como elaborar projetos de pesquisa (4a ed.). São Paulo: Atlas.

Heinz, M. U., Quintana, A. C., \& Capuano, A. P. (2019). Desenvolvimento Cognitivo e Afetivo dos estudantes de Contabilidade - influência do Método de Caso à luz da Taxonomia de Bloom. Revista de Educação e Pesquisa em Contabilidade (REPeC), 13(4), pp. 410-428.Doi: https://doi.org/10.17524/ repec.v13i4.2363

Jackling, B., De Lange, P. A., \& Natoli, R. (2013).Transitioning to IFRS in Australian classrooms: impact on teaching approaches. Issues in Accounting Education, 28(2), pp. 263-275. Doi: 10.2308/iace-50358

Januário, A. H. A., Pinho, C. M. D., Gonçalves, T. J. C., \& Araújo, A. O. (2020). Método do caso: um relato sobre sua efetividade e aplicabilidade no ensino de contabilidade. Revista Ambiente Contábil, 12(1), pp. 317-338. Doi: 10.21680/2176-9036.2020v12n1ID18723

Leal, E. A., \& Borges, M. P. P. (2016). Estratégias de ensino aplicadas na área de contabilidade gerencial: um estudo com discentes do curso de ciências contábeis. Revista Ambiente Contábil, 8(2), ISSN 2176-9036.

Marion, J. C., Garcia, E., \& Cordeiro, M. (2009). Discussão sobre metodologias de ensino aplicáveis à Contabilidade. Contabilidade Vista e Revista, 10(1), pp. 28-33. Recuperado em: https://revistas.face. ufmg.br/index.php/contabilidadevistaerevista/article/view/132

Masetto, M. T. (2003). Competência pedagógica do professor universitário. São Paulo: Summus.

Moura, M. F., Pereira, N. A., Souza, S. T. (2017). Debate: uma técnica de ensino voltada a pluraridade de pontos de vista In: Leal, E. A., Miranda, G. J., \& Casa Nova, S. P. C. Revolucionando a sala de aula: como envolver o estudante aplicando as técnicas de metodologias ativas de aprendizagem (Cap. 5, pp. 53-64). São Paulo: Atlas. 
Nagib, L. R. C. (2018). Relação entre metodologias ativas, ciclo de vida docente e qualificação docente no ensino de graduação em contabilidade (Dissertação). Universidade Federal de Uberlândia - UFU, Minas Gerais, MG, Brasil.

Nagib, L. R. C., \& Silva, D. M. (2020). Adoção de metodologias ativas e sua relação com o ciclo de vida e a qualificação docente no ensino de graduação em ciências contábeis. Revista Contabilidade \& Finanças, 31(82), pp. 145-164. Doi: https://doi.org/10.1590/1808-057x201909030

Oliveira, A. S., \& Campos, L. C. (2017). Grupo de Verbalização/Grupo de Observação (GV-GO). In: Leal, E. A., Miranda, G. J., \& Casa Nova, S. P. C. Revolucionando a sala de aula: como envolver o estudante aplicando as técnicas de metodologias ativas de aprendizagem (Cap. 4, pp. 43-52). São Paulo: Atlas.

Sauaia, A. C. A. (2006). Conhecimento versus desempenho das organizações: Um estudo empírico com jogos de empresas. Revista Eletrônica de Administração, 12(1), pp.1-12. Recuperado em: https:// www.redalyc.org/articulo.oa?id=401137450001

Soares, M. A., Botinha, R. A., Casa Nova, S. P. C., Soares, S. V., Bulaon, C. (2017). Aprendizagem Baseada em Problemas (ABP) ou Problem-Based Learning (PBL): podemos contar com essa alternativa? In: Leal, E. A., Miranda, G. J., \& Casa Nova, S. P. C. Revolucionando a sala de aula: como envolver o estudante aplicando as técnicas de metodologias ativas de aprendizagem (Cap. 9, pp. 105-123). São Paulo: Atlas.

Ott, E., Cunha, J. V. A., Júnior, E. B. C., \& Luca, M. M. M. (2011). Relevância dos conhecimentos, habilidades e métodos instrucionais na perspectiva de estudantes e profissionais da área contábil: estudo comparativo internacional. Revista Contabilidade Financeira, 22(57), pp. 338-356. Doi: https://doi.org/10.1590/S1519-70772011000300007

Thiesen, G. C., Giovanaz, M. P., Rieger, A., \& Bernhard, T. (2017). O júri simulado como estratégica de ensino: trabalhando evolução com turmas do sétimo ano do ensino fundamental. Sala de Ensino e de Extensão: Inovação na Aprendizagem, ISSN 22379193.

Weil, S., Oyelere, P., Yeoh, J., \& Firer, C. (2001). A study of students' perceptions of the usefulness of case studies for the development of finance and accounting-related skills and knowledge. Accounting Education, 10(2), pp. 123-146. Doi: 10.1080/09639280110081642

Wells, M. J. C. (2011). Framework-based approach to teaching principles-based accounting standards. Accounting Education: An International Journal, 20(4), pp. 303-316. Doi: $10.1080 / 09639284.2011 .569128$

Wells, M. J. C., \& Tarca, A. (2014). Estágio 3 - Ativos não financeiros: estudo de caso da Open Safari. London: IFRSF Publications Department, 2014. 